\title{
Multiobjective Game Method Based on Self-Adaptive Space Division of Design Variables and Its Application to Vehicle Suspension
}

\author{
Rui Meng, Nenggang Xie, and Lu Wang \\ School of Mechanical Engineering, Anhui University of Technology, Maanshan, Anhui 243002, China \\ Correspondence should be addressed to Nenggang Xie; xienenggang@aliyun.com
}

Received 10 November 2013; Revised 30 April 2014; Accepted 8 May 2014; Published 15 June 2014

Academic Editor: Gongnan Xie

Copyright (C) 2014 Rui Meng et al. This is an open access article distributed under the Creative Commons Attribution License, which permits unrestricted use, distribution, and reproduction in any medium, provided the original work is properly cited.

\begin{abstract}
Based on the similarity between the game theory and the multiobjective design, the bionic mapping and the space mapping are established between the multiobjective optimization model and game model. Then, the multiobjective optimization method based on self-adaptive space division of design variables is proposed. The design variables are divided into multiple strategy subspaces and are assigned to corresponding game players by calculating impact factors, $K$-means clustering, and correlation analysis. Strategy subspaces of game players are dynamically adjusted in the iteration process. In their own strategy subspaces, each game player takes their payoff function (the mapping of objective function) as monoobjective optimization. It gives the best strategy upon other players. And the best strategies of all players are combined into the group strategy in this game round. Triobjective optimization is carried out for vehicle suspension in this method and it is compared with the traditional game method. The results show that this method has better calculating automaticity and can effectively promote generalization of multiobjective game method and improve the computational efficiency and precision.
\end{abstract}

\section{Instruction}

There are a lot of multiobjective optimization problems in the engineering design. Because the status of objective functions is different and there exists contradiction between the objective functions, it does not generally exist that all objective functions at the same time achieve their optimum solutions. In this case, there exist Pareto optimal solutions (if none of the objective functions can be improved in value without degrading some of the other objective values). Without additional subjective preference information, all Pareto optimal solutions are considered equally good.

Evolutionary algorithms (such as the nondominated sorting genetic algorithm-II (NSGA-II) [1] and strength Pareto evolutionary algorithm 2 (SPEA-2)) [2] are popular approaches to generating Pareto optimal solutions to a multiobjective optimization problem.

Researchers study multiobjective optimization problems from different viewpoints; thus, there exist different solution philosophies and goals when they set and solve them. For a specific engineering optimization problem, the most important goal may be to find a single solution that satisfies the subjective preferences of a human decision maker. In order to obtain a single preferred solution, there mainly exist two kinds of methods. One method refers to establishing the evaluation function by combining multiple objective functions and then monoobjective optimization of evaluation function is performed. The status of the target is reflected by the weight coefficient in this method. Another method refers to first obtaining Pareto optimal solutions and then finding out a single solution by constructing the evaluation index according to the intention of the decision maker.

In recent years, considering the similarity between multiobjective design and the game theory, game method has been used to solve multiobjective design problems, especially for the complicated engineering problems, such as the unmanned spacecraft design [3], satellite attitude control [4], hysteresis inverter design [5], DDM-nozzle optimization [6], 
wing shape design and aerodynamic optimization [7-10], and arch dam shape optimization [11]. In the game method, multiobjective optimization model is first transformed into game model (transformation models include noncooperative game model, cooperative game model, hybrid game model, and evolution game model); then, game model is solved and the game equilibrium solution is the final single solution. The different transformation models have different game equilibrium solutions (the different preferred solutions).

The main advantages of the game method are as follows. (1) The design variables are decomposed into the

the design variables:
the objective functions are minimized:
subject to the constraint conditions:

strategy space owned by each player and the original highdimensional optimization problem is transformed into multiple low-dimensional optimization problems, which can reduce the complexity of problem. (2) Designer can clearly know the correlation between design variables and the objective functions. (3) Optimization objectives are considered to be the different game players and optimization results are seen as game players' mutual negotiation and compromise. Solution through game decision theory has a consistent projection, which means the solution is stable and selfenforced.

A typical minimum multiobjective optimal design can be described as follows:

$$
\begin{aligned}
& X=\left\{\begin{array}{llll}
x_{1} & x_{2} & \cdots & x_{n}
\end{array}\right\} \in \Omega^{n} \\
& F(\mathbf{X})=\left[\begin{array}{lll}
F_{1}(X) & \cdots & F_{m}(X)
\end{array}\right] \longrightarrow \min \\
& a_{i} \leq x_{i} \leq b_{i} \quad(i=1,2, \ldots, n) \\
& h_{l}(X)=0 \quad(l=1,2, \ldots, p) \\
& g_{k}(X) \leq 0 \quad(k=1,2, \ldots, q)
\end{aligned}
$$

where $n$ is the number of variables, $\Omega^{n}$ is the feasible space of design variables, $m$ is the number of objective functions, $b_{i}$ is the upper limit of the design variable $x_{i}, a_{i}$ is the low limit of the design variable $x_{i}, p$ is the number of equality, and $q$ is the number of inequality. Meanwhile, the game model with $m$ players (the number of players equals the number of objective functions) can be written as

$$
G=\left(S_{1}, \ldots, S_{i}, \ldots, S_{m} ; u_{1}, \ldots, u_{i}, \ldots, u_{m}\right),
$$

where $S_{i}$ is the strategy subspace of player $i . u_{i}$ is the payoff function of player $i$.

The available mappings need to be first set up in order to build the general framework of using game method to solve multiobjective optimization problems. Here, two mappings (the bionic mapping and space mapping) are proposed.

(1) The Bionic Mapping (Figure 1). $m$ objectives are considered as $m$ players with behavior modes including competition, cooperation, and evolution. The interaction effect between $m$ players constitutes the game pattern. Functional relationships between payoff functions $\left(u_{i}\right)$ and objective functions $\left(F_{i}\right)$ are set up based on behavior operator including competitive operator, cooperative operator, and evolutional operator.

About the game pattern, the pure competitive pattern exists [6-8, 13-16]; namely, all players adopt competitive behavior to obtain benefit. Pure cooperative pattern also exists $[8,16-18]$; namely, all players adopt the same cooperative behavior to obtain benefit. The typical cooperative behaviors have three types, which are known as the "benefit oneself but do not harm people," "you win to have me, I win to have you," and "all for one and one for all."

For the design objectives with unequal status (designers have target preference), "principal and subordinate" game pattern is constructed [16], such as Stackelberg Oligopoly game model. Because both the strong game player and the weak game player exist in the Stackelberg Oligopoly game model, the satisfaction degree of the game players is different. The strong game player can obtain greater and better satisfaction than the weak game player. Hence, the preferred target can be regarded as the strong game player and the other target can be regarded as the weak game player.

But it is a kind of ideal situation that all the game players adopt the same behavior. In nature and real life, game players have a variety of behaviors and have adaptive ability and dynamic behavior. Hence, mixed game pattern [12] and evolution game pattern [19] are set up.

(2) The Space Mapping (Figure 2). Through the specific method, the design variables $X=\left\{x_{1}, x_{2}, \ldots, x_{n}\right\}$ can be divided into each game player's strategy subspaces $S_{1}, S_{2}, \ldots, S_{m}$ and satisfy $S_{1} \cup \cdots \cup S_{m}=X ; S_{a} \cap S_{b}=0(a, b=$ $1, \ldots, m ; a \neq b)$.

In the game method, the distinctive idea is that the design variables are divided into each player's strategy subspaces. The objective functions are unified in the traditional multiobjective method (such as the mathematical programming method). In contrast, the design variables are divided in the game method. At present, the space division of design variables has empirical method [20] (it is only available to optimization problems with the obvious physical connection or subordinate relations between design variables and objective functions) and fuzzy clustering method in the traditional game method [12] (its disadvantage lies in complex calculation and poor automaticity). In order to solve the above disadvantages, the self-adaptive space division of design variables is proposed based on $K$-means clustering in 


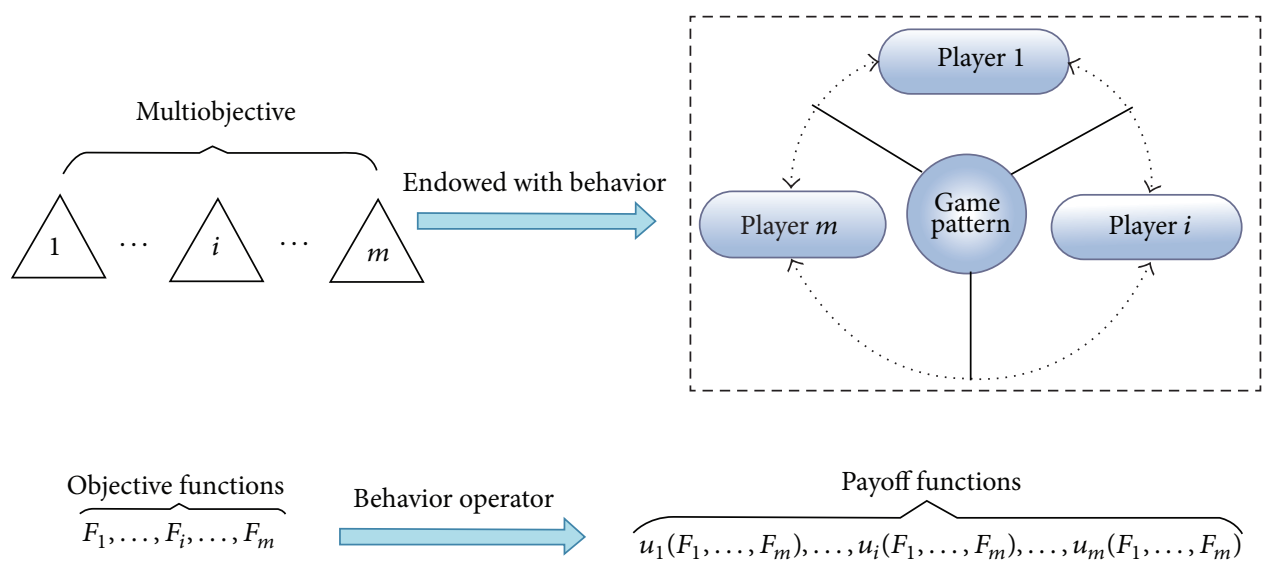

Figure 1: The bionic mapping.
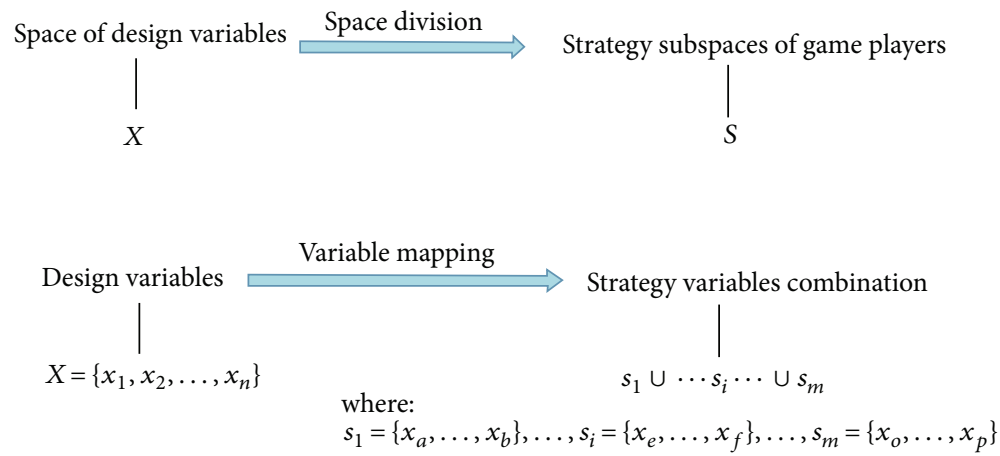

FIGURE 2: The space mapping.

this paper. This method has better calculating automaticity and strategy subspaces of game players are dynamically adjusted in the iteration process. It can effectively promote generalization of multiobjective game method and improve the computational efficiency and precision.

\section{Game Player's Strategy Subspace Computation}

Game player's strategy subspace computation is the key technology in this paper. Section 2 consists of three parts: Section 2.1-K-Means Clustering Method; Section 2.2-Game Player's Strategy Subspace Computation; Section 2.3-The Self-Adaptive Mechanism for Space Division of Design Variables.

2.1. K-Means Clustering Method. Disadvantages of fuzzy clustering in the traditional game method [12] are as follows. (1) The similar approach degree $\left(t_{k l}\right)$ needs to be established and the calculation of $t_{k l}$ is very complex. (2) Fuzzy clustering needs to input system's classification control value $M$ and maximal sample number $P$. The value of $P$ depends on experience judgment of designers, which results in poor performance of automatic calculation.

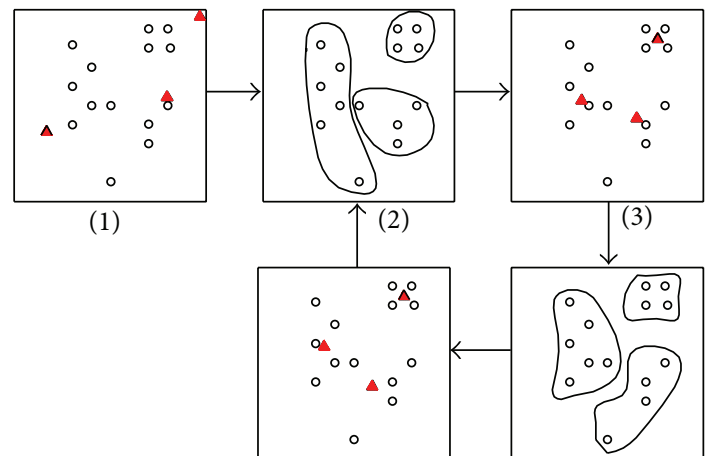

(4)

(5)

Figure 3: The basic idea of $k$-means algorithms.

$K$-means clustering method [21] is adopted in this paper to improve disadvantages above and the basic idea of $k$-means algorithms is shown in Figure 3 and demonstration of solving steps of $k$-means algorithms is as follows.

Step 1. $k$ initial "means" ("mean" is the centers of cluster. In this case $k=3$, they are shown with 3 red triangles in Figure 3) are randomly generated within the data domain (in this case, shown with 14 circles in Figure 3). 
Step 2. $k$ clusters are created by associating every observation with the nearest "mean."

Step 3. The centroid of $k$ clusters becomes the new "mean" based on the results of Step 2 and goes to loop iterations until convergence has been reached.

2.2. Game Player's Strategy Subspace Computation. Impact factors are first calculated in order to form the classification samples and then $K$-means clustering method is adopted to classify the samples and finally strategy subspaces are assigned to corresponding game players by correlation analysis.

\section{(1) Calculation of Impact Factors}

Step 1. Randomly generate $n$ initial values of design variables $\left(X^{(0)}=\left\{x_{1}^{(0)}, x_{2}^{(0)}, \ldots, x_{n}^{(0)}\right\}\right)$ in the feasible space and calculate the corresponding objectives functions $\left(F^{(0)}=\right.$ $\left.\left\{F_{1}^{(0)}, F_{2}^{(0)}, \ldots, F_{m}^{(0)}\right\}\right)$.

Step 2. Every design variable $\left(x_{j}\right)$ is divided into $H$ fragments $(h=(1,2, \ldots, H))$ with step length $\Delta x_{j}$ in its minimal neighborhood; $\Delta_{j i}$ is impact factor of $x_{j}$ affecting $F_{i}$ and is shown as

$$
\begin{aligned}
& \Delta_{j i} \\
& =\left(\sum_{h=1}^{H} \mid F_{i}\left(x_{1}^{(0)}, \ldots, x_{(j-1)}^{(0)}, x_{j}(h), x_{(j+1)}^{(0)}, \ldots, x_{n}^{(0)}\right)\right. \\
& \left.-F_{i}\left(x_{1}^{(0)}, \ldots, x_{(j-1)}^{(0)}, x_{j}(h-1), x_{(j+1)}^{(0)}, \ldots, x_{n}^{(0)}\right) \mid\right) \\
& \times\left(H \cdot \Delta x_{j}\right)^{-1} .
\end{aligned}
$$

To avoid the different function's self-affecting, make normalization processing as follows:

$$
\Delta_{j i}=\frac{\Delta_{j i}}{\sum_{l=1}^{n} \Delta_{l i}} \quad(j=1,2, \ldots, n ; i=1,2, \ldots, m) .
$$

Step 3. Let all samples classification be $\Delta=\left\{\Delta_{1}, \Delta_{2}, \ldots, \Delta_{n}\right\}$, where $\Delta_{j}=\left\{\Delta_{j 1}, \ldots, \Delta_{j m}\right\}(j=1, \ldots, n) . \Delta_{j}$ refers to the impact factors set of design variable $j$ affecting $m$ objective functions.

\section{(2) K-Means Clustering Calculation}

Step 1. Because the design variables must be divided into $m$ strategy subspaces, the clusters number $(K)$ equals the number of objective functions $(m)$; namely, $K=m . m$ initial "means" $\left(\Delta_{c}^{k}=\left\{\Delta_{c 1}^{k}, \ldots, \Delta_{c m}^{k}\right\}(k=1, \ldots, m)\right)$ are far away from each other in order to ensure the satisfaction of clustering, where $\Delta_{c i}^{k} \in[0,1](i=1,2, \ldots, m ; k=$ $1,2, \ldots, m)$.
Step 2. Calculate the distances between $n$ samples $\left(\Delta_{1}, \Delta_{2}, \ldots, \Delta_{n}\right)$ and $m$ initial "means," respectively. If the distance between sample $i$ and "means" $j$ is the nearest, sample $i$ is assigned to "means" $j$ and then $m$ clusters are created by associating every observation with the nearest "mean." Distance is defined as follows:

$$
\begin{gathered}
d\left(\Delta_{c}^{k}, \Delta_{j}\right)=\frac{\sqrt{\sum_{i=1}^{m}\left(\Delta_{c i}^{k}-\Delta_{j i}\right)^{2}}}{m} \\
(k=1,2, \ldots, m ; j=1,2, \ldots, n) .
\end{gathered}
$$

Step 3. Coordinate values of $m$ initial "means" are newly calculated according to

$$
\Delta_{c i}^{k}=\frac{\sum_{j=1}^{D_{k}} \Delta_{j i}}{D_{k}} \quad(i=1,2, \ldots, m ; k=1,2, \ldots, m),
$$

where $D_{k}$ is the number of samples assigned to cluster $k$.

Step 4. Go to Step 2 for loop iterations until $m$ "means" are convergent (namely, they keep unchanged).

Step 5. Clustering results of $\Delta$ stand for the results of $X$ due to the one-to-one correspondence between $\Delta=\left\{\Delta_{1}, \Delta_{2}, \ldots, \Delta_{n}\right\}$ and $X=\left\{x_{1}, x_{2}, \ldots, x_{n}\right\}$. Finally, design variables $X$ are divided into $m$ portions $\left(\mathbf{L}_{1}, \ldots, \mathbf{L}_{m}\right)$.

\section{(3) Correlation Analysis}

Step 1. $\Gamma=\left[\begin{array}{cccc}\Delta_{c 1}^{1} & \Delta_{c 2}^{1} & \cdots & \Delta_{c m}^{1} \\ \Delta_{c 1}^{2} & \Delta_{c 2}^{2} & \cdots & \Delta_{c m}^{2} \\ \vdots & \vdots & \vdots & \vdots \\ \Delta_{c 1}^{m} & \Delta_{c 2}^{m} & \cdots & \Delta_{c m}^{m}\end{array}\right]$ consist of coordinate values of $m$ convergent "means." If the maximum value is $\Delta_{c i}^{k}$, the correlation of the portion $k$ to the objective function $i$ is the strongest. So $L_{k}$ is the subspace of the objective functions $i$ (player $i$ ), which is denoted by $S_{i}$.

Step 2. Delete the row $k$ and column $i$ of the maximum value $\left(\Delta_{c i}^{k}\right)$ and then form matrix with $(m-1)$ rows and $(m-1)$ columns. Repeat Step 1 above until only one number is retained. The last one number decides the affiliation of the last strategy subspace.

\subsection{The Self-Adaptive Mechanism for Space Division of Design} Variables. Strategy subspaces of objective functions (game players) are adjusted adaptively with different game equilibrium solutions. Namely, objective functions own different design variables in different game rounds. For example, the initial design variables values are $X^{(0)}$ for a threeobjective optimization. Strategy subspaces $\left(s_{1}^{(0)}, s_{2}^{(0)}, s_{3}^{(0)}\right)$ of three objectives are obtained based on $X^{(0)}$ according to Section 2.2, which is only used as strategy subspaces in the first round game. Through the first round game, better game equilibrium $\left(X^{(1)}\right)$ is obtained and new strategy subspaces $\left(s_{1}^{(1)}, s_{2}^{(1)}, s_{3}^{(1)}\right)$ of three objectives are obtained, which is only 
used as strategy subspaces of three objectives in the second round game. Because $X^{(0)} \neq X^{(1)},\left(s_{1}^{(0)}, s_{2}^{(0)}, s_{3}^{(0)}\right)$ may not be equal to $\left(s_{1}^{(1)}, s_{2}^{(1)}, s_{3}^{(1)}\right)$. By analogy, strategy subspaces of objective functions can be obtained in the different game rounds.

\section{Multiobjective Game Method Based on Self- Adaptive Space Division of Design Variables}

3.1. Game Pattern. The pure competitive pattern is used in this paper and all players adopt competitive behavior to obtain their own interests. The characteristic of competitive behavior mode is egoism and its corresponding game payoff function is built based on competitive operator. Consider

$$
u_{i}=\frac{F_{i}}{\bar{F}_{i}} \quad(i=1,2, \ldots, m) \text {, }
$$

where $\bar{F}_{i}$ is a reference value, which can eliminate the differences in the magnitude for each objective function. In this paper, the value of initial objective functions is chosen to be $\bar{F}_{i}$.

3.2. The Solution Steps of Game Method Based on SelfAdaptive Space Division of Design Variables. Definition of equilibrium solution of game is as follows. In a game $G=$ $\left(S_{1}, \ldots, S_{m} ; u_{1}, \ldots, u_{m}\right)$, each player's strategy can be assembled into a strategy permutation $\left(s_{1}^{*}, s_{2}^{*} \ldots, s_{m}^{*}\right)$. If an arbitrary game player $i$ 's strategy $s_{i}^{*}$ is the best strategy to all the other players' strategy permutation $\left(s_{1}^{*}, \ldots, s_{i-1}^{*}, s_{i+1}^{*} \ldots, s_{m}^{*}\right)$, then, for any $s_{i j} \in S_{i}$, there exists

$$
\begin{aligned}
& u_{i}\left(s_{1}^{*}, \ldots, s_{i-1}^{*}, s_{i}^{*}, s_{i+1}^{*}, \ldots, s_{m}^{*}\right) \\
& \quad \leq u_{i}\left(s_{1}^{*}, \ldots, s_{i-1}^{*}, s_{i j}, s_{i+1}^{*}, \ldots, s_{m}^{*}\right),
\end{aligned}
$$

where $\left(s_{1}^{*}, s_{2}^{*} \ldots, s_{m}^{*}\right)$ is called an equilibrium solution of game G.

The solution steps of game method based on self-adaptive space division of design variables are as follows.

Step 1. Randomly generate $n$ initial values of design variables in the feasible space; namely, $X^{(0)}=\left\{x_{1}^{(0)}, x_{2}^{(0)}, \ldots, x_{n}^{(0)}\right\}$.

Step 2. The design variables are divided into $m$ strategy subspaces according to Section 2.2 and the mapping is built between the initial design values $X^{(0)}=\left\{x_{1}^{(0)}, x_{2}^{(0)}, \ldots, x_{n}^{(0)}\right\}$ and the initial strategy variables $s^{(0)}=\left\{s_{1}^{(0)}, s_{2}^{(0)}, \ldots, s_{m}^{(0)}\right\}$.

Step 3. Construct the game payoff functions in formula (7); namely, $u_{i}=\left(F_{i} / \bar{F}_{i}\right)(i=1,2, \ldots, m)$.
Step 4. Let $\bar{s}_{1}^{(0)}, \bar{s}_{2}^{(0)}, \ldots, \bar{s}_{m}^{(0)}$ be the corresponding complementary set of $s_{1}^{(0)}, s_{2}^{(0)}, \ldots, s_{m}^{(0)}$ in $s^{(0)}$. For any player $i(i=$ $1,2, \ldots, m)$, solve the optimal strategy $s_{i}^{*} \in \mathbf{S}_{i}$ and make $u_{i}\left(s_{i}^{*}, \bar{s}_{i}^{(0)}\right) \rightarrow \min$.

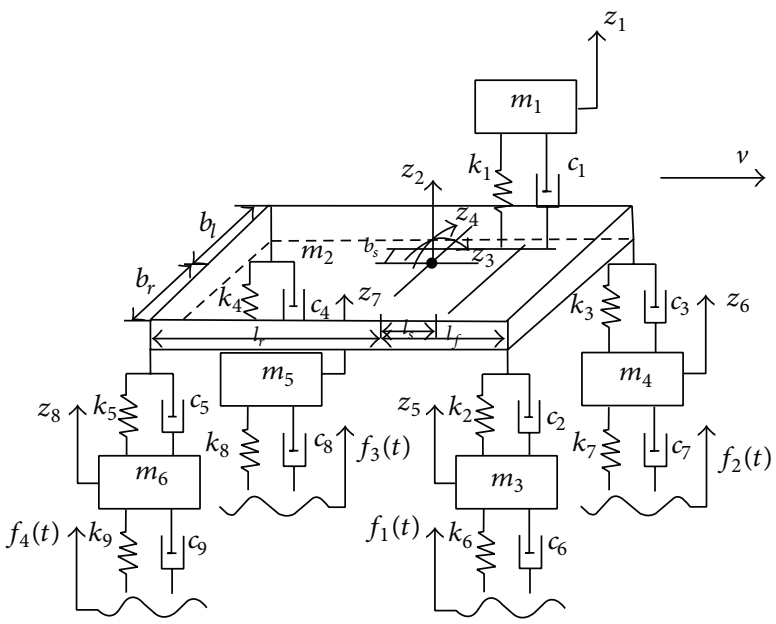

FIGURE 4: Dynamic model of 8 DOF for full vehicle suspension.

Step 5. Define strategy permutation $s^{(1)}=s_{1}^{*} \cup s_{2}^{*} \cup \cdots \cup s_{m}^{*}$; then judge the feasibility of $s^{(1)}$. If it does not satisfy constraint condition, turn to Step 1. Otherwise, compute the distance between $s^{(1)}$ and $s^{(0)}$, which is called the Euclidean norm. Then, examine whether the distance satisfies the convergence criterion $\left\|s^{(1)}-s^{(0)}\right\|=\sqrt{\sum_{j=1}^{n}\left\{\left[\left(x_{j}^{*}-x_{j}^{(0)}\right) / x_{j}^{(0)}\right]^{2} / n\right\}} \leq \varepsilon$ or not ( $\varepsilon$ is a decimal parameter; in this paper, $\varepsilon=0.0001$ ). If it satisfies, the game is over; if not, $X^{(1)}$ displaces $X^{(0)}$ and turns to Step 2 for loop iteration.

\section{Triobjective Optimization of Parameters for Passive Suspension}

4.1. Dynamic Model of 8 Degrees of Freedom (DOF) for Full Vehicle Suspension. A full vehicle model with 8 DOF is considered for analysis, as shown in Figure 4. All the symbols are shown in Table 9. The kinetic equation of the suspension system is given as follows [12]:

$$
[\mathbf{M}]\{\ddot{Z}\}+[\mathbf{C}]\{\dot{Z}\}+[\mathbf{K}]\{Z\}=[\mathbf{F}],
$$

where $\{Z\}$ is a displacement array, $\{\dot{Z}\}$ is a speed array, and $\{\ddot{Z}\}$ is an acceleration array; $\{Z\}=\left\{\begin{array}{llll}z_{1} & z_{2} & \cdots & z_{8}\end{array}\right\}^{T}$. $[\mathbf{M}]$ is a mass matrix, $[\mathbf{C}]$ is a damping matrix, $[\mathbf{K}]$ is a stiffness matrix, and $[\mathbf{F}]$ is a pavement excitation matrix. $[\mathbf{M}]=\operatorname{diag}\left\{\begin{array}{llllllll}m_{1} & m_{2} & I_{p} & I_{r} & m_{3} & m_{4} & m_{5} & m_{6}\end{array}\right\} ; I_{p}$ is moment of inertia for pitch and $I_{r}$ is moment of inertia for roll.

Consider 


$$
\begin{aligned}
& {[\mathbf{C}]=\left[\begin{array}{ccc}
c_{1} & -c_{1} & c_{1} l_{s} \\
-c_{1} & c_{1}+c_{2}+c_{3}+c_{4}+c_{5} & -c_{1} l_{s}-c_{2} l_{f}-c_{3} l_{f}+c_{4} l_{r}+c_{5} l_{r} \\
c_{1} l_{s} & -c_{1} l_{s}-c_{2} l_{f}-c_{3} l_{f}+c_{4} l_{r}+c_{5} l_{r} & c_{1} l_{s}^{2}+c_{2} l_{f}^{2}+c_{3} l_{f}^{2}+c_{4} l_{r}^{2}+c_{5} l_{r}^{2} \\
c_{1} b_{s} & -c_{1} b_{s}+c_{2} b_{r}-c_{3} b_{l}-c_{4} b_{l}+c_{5} b_{r} & c_{1} b_{s} l_{s}-c_{2} b_{r} l_{f}+c_{3} b_{l} l_{f}-c_{4} b_{l} l_{r}+c_{5} b_{r} l_{r} \\
0 & -c_{2} & c_{2} l_{f} \\
0 & -c_{3} & c_{3} l_{f} \\
0 & -c_{4} & -c_{4} l_{r} \\
0 & -c_{5} & -c_{5} l_{r}
\end{array}\right.} \\
& \left.\begin{array}{ccccc}
c_{1} b_{s} & 0 & 0 & 0 & 0 \\
-c_{1} b_{s}+c_{2} b_{r}-c_{3} b_{l}-c_{4} b_{1}+c_{5} b_{r} & -c_{2} & -c_{3} & -c_{4} & -c_{5} \\
c_{1} l_{s} b_{s}-c_{2} b_{r} l_{f}+c_{3} b_{l} l_{f}-c_{4} b_{l} l_{r}+c_{5} l_{r} b_{r} & c_{2} l_{f} & c_{3} l_{f} & -c_{4} l_{r} & -c_{5} l_{r} \\
c_{1} b_{s}^{2}+c_{2} b_{r}^{2}+c_{3} b_{l}^{2}+c_{4} b_{l}^{2}+c_{5} b_{r}^{2} & -c_{2} b_{r} & c_{3} b_{l} & c_{4} b_{l} & -c_{5} b_{r} \\
-c_{2} b_{r} & c_{2}+c_{6} & 0 & 0 & 0 \\
c_{3} b_{l} & 0 & c_{3}+c_{7} & 0 & 0 \\
c_{4} b_{l} & 0 & 0 & c_{4}+c_{8} & 0 \\
-c_{5} b_{r} & 0 & 0 & 0 & c_{5}+c_{9}
\end{array}\right] \\
& {[\mathbf{K}]=\left[\begin{array}{ccc}
k_{1} & -k_{1} & k_{1} l_{s} \\
-k_{1} & k_{1}+k_{2}+k_{3}+k_{4}+k_{5} & -k_{1} l_{s}-k_{2} l_{f}-k_{3} l_{f}+k_{4} l_{r}+k_{5} l_{r} \\
k_{1} l_{s} & -k_{1} l_{s}-k_{2} l_{f}-k_{3} l_{f}+k_{4} l_{r}+k_{5} l_{r} & k_{1} l_{s}^{2}+k_{2} l_{f}^{2}+k_{3} l_{f}^{2}+k_{4} l_{r}^{2}+k_{5} l_{r}^{2} \\
k_{1} b_{s} & -k_{1} b_{s}+k_{2} b_{r}-k_{3} b_{l}-k_{4} b_{1}+k_{5} b_{r} & k_{1} b_{s} l_{s}-k_{2} b_{r} l_{f}+k_{3} b_{l} l_{f}-k_{4} b_{l} l_{r}+k_{5} b_{r} l_{r} \\
0 & -k_{2} & k_{2} l_{f} \\
0 & -k_{3} & k_{3} l_{f} \\
0 & -k_{4} & -k_{4} l_{r} \\
0 & -k_{5} & -k_{5} l_{r}
\end{array}\right.} \\
& \left.\begin{array}{ccccc}
k_{1} b_{s} & 0 & 0 & 0 & 0 \\
-k_{1} b_{s}+k_{2} b_{r}-k_{3} b_{l}-k_{4} b_{l}+k_{5} b_{r} & -k_{2} & -k_{3} & -k_{4} & -k_{5} \\
k_{1} l_{s} b_{s}-k_{2} b_{r} l_{f}+k_{3} b_{l} l_{f}-k_{4} b_{l} l_{r}+k_{5} l_{r} b_{r} & k_{2} l_{f} & k_{3} l_{f} & -k_{4} l_{r} & -k_{5} l_{r} \\
k_{1} b_{s}^{2}+k_{2} b_{r}^{2}+k_{3} b_{l}^{2}+k_{4} b_{l}^{2}+k_{5} b_{r}^{2} & -k_{2} b_{r} & k_{3} b_{l} & k_{4} b_{l} & -k_{5} b_{r} \\
-k_{2} b_{r} & k_{2}+k_{6} & 0 & 0 & 0 \\
k_{3} b_{l} & 0 & k_{3}+k_{7} & 0 & 0 \\
k_{4} b_{l} & 0 & 0 & k_{4}+k_{8} & 0 \\
-k_{5} b_{r} & 0 & 0 & 0 & k_{5}+k_{9}
\end{array}\right]
\end{aligned}
$$

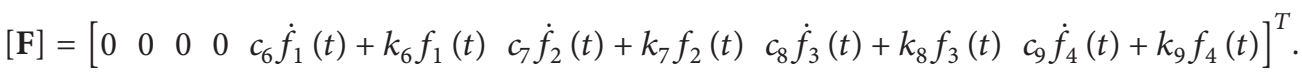

\subsection{Multiobjective Optimization Design Model}

4.2.1. Design Variables. Vehicle seat, suspension damping, and stiffness are selected as the design variables. The damping and stiffness have the same values on the left and right side due to vehicle symmetry; that is, $k_{3}=k_{2}, k_{5}=k_{4}$, $c_{3}=c_{2}$, and $c_{5}=c_{4}$, and the design variables are $X=$ $\left\{x_{1}, x_{2}, x_{3}, x_{4}, x_{5}, x_{6}\right\}=\left\{k_{1}, c_{1}, k_{2}, c_{2}, k_{4}, c_{4}\right\}$.

4.2.2. Objective Functions. Take ride comfort (RMS of acceleration of the seat), damage of vehicles on the road (RMS of the tire relative to dynamic load), and ride comfort (the maximum dynamic stroke suspension) as objective functions [12], denoted by $F_{1}, F_{2}$, and $F_{3}$.

Let RMS of acceleration of the seat be optimization objective $F_{1}$.

\section{Consider}

$$
F_{1}=\left[\frac{1}{T} \int_{0}^{T} \ddot{z}_{1}^{2}(t) d t\right]^{1 / 2} \longrightarrow \min
$$

where $T$ is the total driving time $(0 \leq t \leq T)$.

Let RMS of relative dynamic loading of tire be optimization objective $F_{2}$.

Consider

$$
\begin{aligned}
F_{2}=\left[\frac{1}{T} \int_{0}^{T}\{\right. & \left(\frac{F_{d 1}(t)}{G_{1}}+\frac{F_{d 2}(t)}{G_{2}}+\frac{F_{d 3}(t)}{G_{3}}+\frac{F_{d 4}(t)}{G_{4}}\right) \\
& \left.\left.\times(4)^{-1}\right\}^{2} d t\right]^{1 / 2} \longrightarrow \mathrm{min},
\end{aligned}
$$


TABLE 1: Impact factors of $X^{(0)}$ affecting the objective functions.

\begin{tabular}{cccccc}
\hline Impact factors $\Delta_{j i}$ & $x_{1}$ & $x_{2}$ & $x_{3}$ & $x_{4}$ & $x_{5}$ \\
\hline Objective functions & & & & \\
$F_{1}$ & 0.0029 & 0.8437 & 0.0159 & 0.0711 & 0.0103 \\
$F_{2}$ & 0.0001 & 0.0313 & 0.0998 & 0.4362 & 0.1134 \\
$F_{3}$ & 0.0195 & 0.2344 & 0.4377 & 0.2647 & 0.0561 \\
\hline
\end{tabular}

TABLE 2: Impact factors of $X^{(1)}$ affecting the objective functions.

\begin{tabular}{|c|c|c|c|c|c|c|}
\hline \multirow{2}{*}{ Impact factors $\Delta_{j i}$} & \multicolumn{6}{|c|}{ Design variables } \\
\hline & $x_{1}$ & $x_{2}$ & $x_{3}$ & $x_{4}$ & $x_{5}$ & $x_{6}$ \\
\hline \multicolumn{7}{|l|}{ Objective functions } \\
\hline$F_{1}$ & 0.0004 & 0.8253 & 0.0189 & 0.0855 & 0.0074 & 0.0626 \\
\hline$F_{2}$ & 0.0004 & 0.0307 & 0.0552 & 0.2400 & 0.2156 & 0.4581 \\
\hline$F_{3}$ & 0.0038 & 0.0146 & 0.0194 & 0.1908 & 0.0579 & 0.7136 \\
\hline
\end{tabular}

TABLE 3: Impact factors of $X^{(2)}$ affecting the objective functions.

\begin{tabular}{|c|c|c|c|c|c|c|}
\hline \multirow{2}{*}{ Impact factors $\Delta_{j i}$} & \multicolumn{6}{|c|}{ Design variables } \\
\hline & $x_{1}$ & $x_{2}$ & $x_{3}$ & $x_{4}$ & $x_{5}$ & $x_{6}$ \\
\hline \multicolumn{7}{|l|}{ Objective functions } \\
\hline$F_{1}$ & 0.0065 & 0.7535 & 0.0172 & 0.1153 & 0.0140 & 0.0934 \\
\hline$F_{2}$ & 0.0010 & 0.0556 & 0.1105 & 0.3244 & 0.1577 & 0.3508 \\
\hline$F_{3}$ & 0.0015 & 0.0085 & 0.0773 & 0.7323 & 0.0194 & 0.1609 \\
\hline
\end{tabular}

TABLE 4: Impact factors of $X^{(3)}$ affecting the objective functions.

\begin{tabular}{|c|c|c|c|c|c|c|}
\hline \multirow{2}{*}{ Impact factors $\Delta_{j i}$} & \multicolumn{6}{|c|}{ Design variables } \\
\hline & $x_{1}$ & $x_{2}$ & $x_{3}$ & $x_{4}$ & $x_{5}$ & $x_{6}$ \\
\hline \multicolumn{7}{|l|}{ Objective functions } \\
\hline$F_{1}$ & 0.0402 & 0.7721 & 0.0085 & 0.0978 & 0.0027 & 0.0788 \\
\hline$F_{2}$ & 0.0173 & 0.0160 & 0.1129 & 0.5041 & 0.0880 & 0.2617 \\
\hline$F_{3}$ & 0.0078 & 0.1073 & 0.2521 & 0.5603 & 0.0034 & 0.0691 \\
\hline
\end{tabular}

TABLE 5: Design variables values and objective functions values of the different game rounds.

\begin{tabular}{lccccccccc}
\hline Game round & $\begin{array}{c}x_{1} \\
(\mathrm{KN} / \mathrm{m})\end{array}$ & $\begin{array}{c}x_{2} \\
(\mathrm{~N} \cdot \mathrm{S} / \mathrm{m})\end{array}$ & $\begin{array}{c}x_{3} \\
(\mathrm{KN} / \mathrm{m})\end{array}$ & $\begin{array}{c}x_{4} \\
(\mathrm{KN} \cdot \mathrm{S} / \mathrm{m})\end{array}$ & $\begin{array}{c}x_{5} \\
(\mathrm{KN} / \mathrm{m})\end{array}$ & $\begin{array}{c}x_{6} \\
(\mathrm{KN} \cdot \mathrm{S} / \mathrm{m})\end{array}$ & $\begin{array}{c}F_{1} \\
\left(\mathrm{~m} / \mathrm{s}^{2}\right)\end{array}$ & $\begin{array}{c}F_{2} \\
(\mathrm{~mm})\end{array}$ \\
\hline 0 & 15.000 & 150.000 & 15.000 & 2.500 & 17.000 & 2.500 & 0.0815 & 0.0264 & 5.245 \\
1 & 16.466 & 224.926 & 20.815 & 1.843 & 11.303 & 2.183 & 0.0893 & 0.0267 & 5.283 \\
2 & 22.285 & 224.926 & 20.539 & 1.682 & 23.590 & 2.525 & 0.1067 & 0.0223 & 5.989 \\
3 & 13.721 & 224.926 & 21.142 & 3.718 & 24.574 & 3.313 & 0.0674 & 0.0245 & 4.272 \\
4 & 13.722 & 224.926 & 21.142 & 3.718 & 24.573 & 3.313 & 0.0674 & 0.0245 & 4.272 \\
\hline
\end{tabular}

TABLE 6: Strategy subspaces in this paper.

\begin{tabular}{lccc}
\hline Game round & $S_{1}$ & $S_{2}$ & $S_{3}$ \\
\hline 1 & $x_{2}$ & $x_{3}, x_{4}, x_{6}$ & $x_{1}, x_{5}$ \\
2 & $x_{2}$ & $x_{1}, x_{3}, x_{4}, x_{5}$ & $x_{6}$ \\
3 & $x_{2}$ & $x_{1}, x_{3}, x_{5}, x_{6}$ & $x_{4}$ \\
4 & $x_{2}$ & $x_{1}, x_{3}, x_{5}, x_{6}$ & $x_{4}$ \\
\hline
\end{tabular}

TABLE 7: Strategy subspaces in the traditional game method.

\begin{tabular}{lccc}
\hline Game round & $S_{1}$ & $S_{2}$ & $S_{3}$ \\
\hline $1 \sim 6$ & $x_{1}, x_{2}$ & $x_{3}, x_{6}$ & $x_{4}, x_{5}$ \\
\hline & \\
where $G_{1}=m_{2} g\left(l_{r} /\left(l_{f}+l_{r}\right)\right)\left(b_{l} /\left(b_{l}+b_{r}\right)\right), G_{2}=m_{2} g\left(l_{r} /\left(l_{f}+\right.\right.$ \\
$\left.\left.l_{r}\right)\right)\left(b_{r} /\left(b_{l}+b_{r}\right)\right), G_{3}=m_{2} g\left(l_{f} /\left(l_{f}+l_{r}\right)\right)\left(b_{r} /\left(b_{l}+b_{r}\right)\right)$, and
\end{tabular}


TABLE 8: Comparison of objective functions values between initial design, the traditional game method, and this paper.

\begin{tabular}{|c|c|c|c|c|c|c|c|c|c|}
\hline Design method & $\begin{array}{c}x_{1} \\
(\mathrm{KN} / \mathrm{m})\end{array}$ & $\begin{array}{c}x_{2} \\
(\mathrm{~N} \cdot \mathrm{S} / \mathrm{m})\end{array}$ & $\begin{array}{c}x_{3} \\
(\mathrm{KN} / \mathrm{m})\end{array}$ & $\begin{array}{c}x_{4} \\
(\mathrm{KN} \cdot \mathrm{S} / \mathrm{m})\end{array}$ & $\begin{array}{c}x_{5} \\
(\mathrm{KN} / \mathrm{m})\end{array}$ & $\begin{array}{c}x_{6} \\
(\mathrm{KN} \cdot \mathrm{S} / \mathrm{m})\end{array}$ & $\begin{array}{c}F_{1} \\
\left(\mathrm{~m} / \mathrm{s}^{2}\right)\end{array}$ & $F_{2}$ & $\begin{array}{c}F_{3} \\
(\mathrm{~mm})\end{array}$ \\
\hline The initial design & 15.000 & 150.000 & 15.000 & 2.500 & 17.000 & 2.500 & 0.0815 & 0.0264 & 5.245 \\
\hline $\begin{array}{l}\text { The traditional game } \\
\text { method-egoism design [12] }\end{array}$ & 10.532 & 220.217 & 20.432 & 3.716 & 23.277 & 2.019 & 0.0699 & 0.0246 & 4.402 \\
\hline This paper & 13.722 & 224.926 & 21.142 & 3.718 & 24.573 & 3.313 & 0.0674 & 0.0245 & 4.272 \\
\hline
\end{tabular}

$G_{4}=m_{2} g\left(l_{f} /\left(l_{f}+l_{r}\right)\right)\left(b_{l} /\left(b_{l}+b_{r}\right)\right)$ are static loads of four wheels. $F_{d 1}, F_{d 2}, F_{d 3}$, and $F_{d 4}$ are dynamic loads of four wheels.

Consider

$$
\begin{aligned}
F_{d 1}= & c_{2}\left(\dot{z}_{5}-\dot{z}_{2}+l_{f} \dot{z}_{3}-b_{r} \dot{z}_{4}\right) \\
& +k_{2}\left(z_{5}-z_{2}+l_{f} z_{3}-b_{r} z_{4}\right)+m_{3} \ddot{z}_{5} ; \\
F_{d 2}= & c_{3}\left(\dot{z}_{6}-\dot{z}_{2}+l_{f} \dot{z}_{3}+b_{l} \dot{z}_{4}\right) \\
& +k_{3}\left(z_{6}-z_{2}+l_{f} z_{3}+b_{l} z_{4}\right)+m_{4} \ddot{z}_{6} ; \\
F_{d 3}= & c_{4}\left(\dot{z}_{7}-\dot{z}_{2}-l_{r} \dot{z}_{3}+b_{l} \dot{z}_{4}\right) \\
& +k_{4}\left(z_{7}-z_{2}-l_{r} z_{3}+b_{l} z_{4}\right)+m_{5} \ddot{z}_{7} ; \\
F_{d 4}= & c_{5}\left(\dot{z}_{8}-\dot{z}_{2}-l_{r} \dot{z}_{3}-b_{r} \dot{z}_{4}\right) \\
& +k_{5}\left(z_{8}-z_{2}-l_{r} z_{3}-b_{r} z_{4}\right)+m_{6} \ddot{z}_{8} .
\end{aligned}
$$

Let the maximum value of dynamic travel among four suspensions of right front, left front, left rear, and right rear be optimization objective $F_{3}$.

Consider

$$
F_{3}=\max _{i \in\{1,2,3,4\}}\left\{\max _{t \in[0, T]}\left[f_{d i}(t)\right]\right\} \rightarrow \min ,
$$

where $f_{d 1}=z_{2}-l_{f} z_{3}+b_{r} z_{4}-z_{5}, f_{d 2}=z_{2}-l_{f} z_{3}-b_{l} z_{4}-z_{6}$, $f_{d 3}=z_{2}+l_{r} z_{3}-b_{l} z_{4}-z_{7}$, and $f_{d 4}=z_{2}+l_{r} z_{3}+b_{r} z_{4}-z_{8}$ are the suspension dynamic travel distance.

4.2.3. Constraint Conditions. The suspension stroke $f_{d}$ is defined as the maximum compression distance allowed by the suspension from the equilibrium position of vehicle. Suspension stroke $f_{d}$ should be appropriate with $\left[f_{d}\right]$. Otherwise, the suspension will hit against the block frequently. The suspension stroke must satisfy constraint condition $0 \leq$ $f_{d i} \leq\left[f_{d}\right](i=1,2,3,4)$.

\section{Calculation and Analysis}

5.1. Computational Illustrations. According to a particular vehicle, the parameters of the paper are in [22] and the values are in Table 9. Time-domain data of roughness for the left and right front wheels can be seen in Figure 3 [12] and Figure 4 [12].

5.2. Computation Process. Initial design variables are $x_{1}=$ $15.000(\mathrm{KN} / \mathrm{m}), x_{2}=150.000(\mathrm{~N} \cdot \mathrm{S} / \mathrm{m}), x_{3}=15.000$
$(\mathrm{KN} / \mathrm{m}), x_{4}=2.500(\mathrm{KN} \cdot \mathrm{S} / \mathrm{m}), x_{5}=17.000(\mathrm{KN} / \mathrm{m})$, and $x_{6}=2.500(\mathrm{KN} \cdot \mathrm{S} / \mathrm{m}) ; X^{(0)}=\left\{x_{1}^{(0)}, x_{2}^{(0)}, \ldots, x_{6}^{(0)}\right\}=$ $(15,150,15,2.5,17,2.5)$. Impact factors of $X^{(0)}$ affecting the objective functions are shown in Table 1.

Cluster 1 consists of design variables $x_{3}, x_{4}$, and $x_{6}$ and cluster 2 consists of design variables $x_{2}$ and cluster 3 consists of design variables $x_{1}$ and $x_{5}$ by clustering calculation. Correlation analysis is as follows:

(1) $\Gamma=\left[\begin{array}{lll}0.0477 & 0.2851 & 0.2443 \\ 0.8437 & 0.0313 & 0.2344 \\ 0.0066 & 0.0567 & 0.0164\end{array}\right]$ consist of coordinate values of three convergent "means." Because the maximum value is 0.8437 in $\Gamma$, cluster 2 is the strategy subspace of $F_{1}$, which is denoted by $S_{1}$.

(2) Row 2 and column 1 of the maximum value (0.8437) are deleted and then $\Gamma^{\prime}=\left[\begin{array}{ll}0.2851 & 0.2443 \\ 0.0567 & 0.0164\end{array}\right]$ is newly built. Because the maximum value is 0.2851 in $\Gamma^{\prime}$, cluster 1 is the strategy subspace of $F_{2}$, which is denoted by $S_{2}$.

(3) Row 1 and column 1 of the maximum value (0.2851) are deleted and only one number $(0.0164)$ is left. The last number (0.0164) decides the affiliation of the last strategy subspace; namely, cluster 3 is the strategy subspace of $F_{3}$, which is denoted by $S_{3}$.

Namely, $S_{1}=\left\{x_{2}\right\}$ is the strategy subspace of $F_{1}, S_{2}=$ $\left\{x_{3}, x_{4}, x_{6}\right\}$ is the strategy subspace of $F_{2}$, and $S_{3}=\left\{x_{1}, x_{5}\right\}$ is the strategy subspace of $F_{3}$.

The game equilibrium solutions are $X^{(1)}=\left(x_{1}^{*}, x_{2}^{*}, \ldots\right.$, $\left.x_{6}^{*}\right)=(16.466,224.926,20.815,1.843,11.303,2.183)$ after the first round iteration. Because it does not satisfy the convergence $\left(\sqrt{\sum_{j=1}^{6}\left\{\left[\left(X^{(1)}-X^{(0)}\right) / x_{j}^{(0)}\right]^{2} / 6\right\}}>\varepsilon, \varepsilon=0.0001\right)$, the second game round is needed.

Impact factors of $X^{(1)}$ affecting the objective functions are shown in Table 2. Cluster 1 consists of design variables $x_{6}$ and cluster 2 consists of design variables $x_{2}$ and cluster 3 consists of design variables $x_{1}, x_{3}, x_{4}$, and $x_{5}$ by $K$-means clustering calculation.

$\Gamma=\left[\begin{array}{lll}0.0626 & 0.4581 & 0.7136 \\ 0.8253 & 0.0307 & 0.0146 \\ 0.0280 & 0.1278 & 0.0679\end{array}\right]$ consist of coordinate values of three convergent "means." $S_{1}=\left\{x_{2}\right\}$ is the strategy subspace of $F_{1}$ and $S_{2}=\left\{x_{1}, x_{3}, x_{4}, x_{5}\right\}$ is the strategy subspace of $F_{2}$ and $S_{3}=\left\{x_{6}\right\}$ is the strategy subspace of $F_{3}$ by correlation analysis. 
TABle 9

\begin{tabular}{|c|c|c|c|}
\hline Symbol & Parameters name & Unit & Value \\
\hline$z_{1}$ & Vertical driver seat DOF & $\mathrm{m}$ & Dynamic varying range \\
\hline$z_{2}$ & Vertical body displacement DOF & $\mathrm{m}$ & Dynamic varying range \\
\hline$z_{3}$ & Pitching DOF & $\mathrm{rad}$ & Dynamic varying range \\
\hline$z_{4}$ & Roll DOF & $\mathrm{rad}$ & Dynamic varying range \\
\hline$z_{5}$ & Front right wheel's vertical DOF & $\mathrm{m}$ & Dynamic varying range \\
\hline$z_{6}$ & Front left wheel's vertical DOF & $\mathrm{m}$ & Dynamic varying range \\
\hline$z_{7}$ & Back right wheel's vertical DOF & $\mathrm{m}$ & Dynamic varying range \\
\hline$z_{8}$ & Back left wheel's vertical DOF & $\mathrm{m}$ & Dynamic varying range \\
\hline$q_{1}(t)$ & Front right wheel road roughness incentives & $\mathrm{m}$ & Input data \\
\hline$q_{2}(t)$ & Front left wheel road roughness incentives & $\mathrm{m}$ & Input data \\
\hline$q_{3}(t)$ & Back left wheel road roughness incentives & $\mathrm{m}$ & Input data \\
\hline$q_{4}(t)$ & Back right wheel road roughness incentives & $\mathrm{m}$ & Input data \\
\hline$k_{1}$ & Driver seat's spring stiffness coefficient & $\mathrm{kN} / \mathrm{m}$ & $7.5 \leq k_{1}=x_{1} \leq 22.5$ initial 15 \\
\hline$k_{2}$ & Front right suspension spring stiffness coefficient & $\mathrm{kN} / \mathrm{m}$ & $7.5 \leq k_{2}=x_{3} \leq 22.5$ initial 15 \\
\hline$k_{3}$ & Front left suspension spring stiffness coefficient & $\mathrm{kN} / \mathrm{m}$ & $7.5 \leq k_{3}=x_{3} \leq 22.5$ initial 15 \\
\hline$k_{4}$ & Back left suspension spring stiffness coefficient & $\mathrm{kN} / \mathrm{m}$ & $8.5 \leq k_{4}=x_{5} \leq 25.5$ initial 17 \\
\hline$k_{5}$ & Back right suspension spring stiffness coefficient & $\mathrm{kN} / \mathrm{m}$ & $8.5 \leq k_{5}=x_{5} \leq 25.5$ initial 17 \\
\hline$k_{6}$ & Front right tire spring stiffness coefficient & $\mathrm{kN} / \mathrm{m}$ & 250 \\
\hline$k_{7}$ & Front left tire spring stiffness coefficient & $\mathrm{kN} / \mathrm{m}$ & 250 \\
\hline$k_{8}$ & Back left tire spring stiffness coefficient & $\mathrm{kN} / \mathrm{m}$ & 250 \\
\hline$k_{9}$ & Back right tire spring stiffness coefficient & $\mathrm{kN} / \mathrm{m}$ & 250 \\
\hline$c_{1}$ & Driver seat's damping coefficient & $\mathrm{N} \cdot \mathrm{s} / \mathrm{m}$ & $75 \leq c_{1}=x_{2} \leq 225$ initial 150 \\
\hline$c_{2}$ & Front right suspension damping coefficient & $\mathrm{kN} \cdot \mathrm{s} / \mathrm{m}$ & $1.25 \leq c_{2}=x_{4} \leq 3.75$ initial 2.5 \\
\hline$c_{3}$ & Front left suspension damping coefficient & $\mathrm{kN} \cdot \mathrm{s} / \mathrm{m}$ & $1.25 \leq c_{3}=x_{4} \leq 3.75$ initial 2.5 \\
\hline$c_{4}$ & Back left suspension damping coefficient & $\mathrm{kN} \cdot \mathrm{s} / \mathrm{m}$ & $1.25 \leq c_{5}=x_{6} \leq 3.75$ initial 2.5 \\
\hline$c_{5}$ & Back right suspension damping coefficient & $\mathrm{kN} \cdot \mathrm{s} / \mathrm{m}$ & $1.25 \leq c_{6}=x_{6} \leq 3.75$ initial 2.5 \\
\hline$c_{6}$ & Front right tire spring damping coefficient & $\mathrm{kN} \cdot \mathrm{s} / \mathrm{m}$ & 0.15 \\
\hline$c_{7}$ & Front left tire spring damping coefficient & $\mathrm{kN} \cdot \mathrm{s} / \mathrm{m}$ & 0.15 \\
\hline$c_{8}$ & Back left tire spring damping coefficient & $\mathrm{kN} \cdot \mathrm{s} / \mathrm{m}$ & 0.15 \\
\hline$c_{9}$ & Back right tire spring damping coefficient & $\mathrm{kN} \cdot \mathrm{s} / \mathrm{m}$ & 0.15 \\
\hline$m_{1}$ & Driver seat mass & $\mathrm{kg}$ & 90 \\
\hline$m_{2}$ & Suspension mass & $\mathrm{kg}$ & 1100 \\
\hline$m_{3}$ & Front right tire's mass & $\mathrm{kg}$ & 25 \\
\hline$m_{4}$ & Front left tire's mass & $\mathrm{kg}$ & 25 \\
\hline$m_{5}$ & Back left tire’s mass & $\mathrm{kg}$ & 45 \\
\hline$m_{6}$ & Back right tire's mass & $\mathrm{kg}$ & 45 \\
\hline$I_{r}$ & Roll moment of inertia & $\mathrm{kg} \cdot \mathrm{m}^{2}$ & 550 \\
\hline$I_{p}$ & Pitch moment of inertia & $\mathrm{kg} \cdot \mathrm{m}^{2}$ & 1848 \\
\hline$l_{f}$ & Body mass center to front axle distance & $\mathrm{m}$ & 1.2 \\
\hline$l_{r}$ & Body mass center to back axle distance & $\mathrm{m}$ & 1.4 \\
\hline$l_{s}$ & Vertical body mass distance between seats & $\mathrm{m}$ & 0.3 \\
\hline$b_{l}$ & Body mass to left wheel distance & $\mathrm{m}$ & 1.0 \\
\hline$b_{r}$ & Body mass to right wheel distance & $\mathrm{m}$ & 0.5 \\
\hline$b_{s}$ & Body mass seat to the horizontal distance & $\mathrm{m}$ & 0.25 \\
\hline$v$ & Vehicle’s driving velocity & $\mathrm{m} / \mathrm{s}$ & 20 \\
\hline$\left[f_{d}\right]$ & The suspension's restricted maximum compression stroke & $\mathrm{m}$ & 0.1 \\
\hline$T$ & Driving time & s & 120 \\
\hline
\end{tabular}


The game equilibrium solutions are $X^{(2)}=\left(x_{1}^{*}, x_{2}^{*}, \ldots\right.$, $\left.x_{6}^{*}\right)=(22.285,224.926,20.539,1.682,23.590,2.525)$ after the second round iteration. Because it does not satisfy the convergence, the third game round is needed.

Impact factors of $X^{(2)}$ affecting the objective functions are shown in Table 3. Cluster 1 consists of design variables $x_{4}$ and cluster 2 consists of design variables $x_{2}$ and cluster 3 consists of design variables $x_{1}, x_{3}, x_{5}$, and $x_{6}$ by clustering calculation.

$\Gamma=\left[\begin{array}{lll}0.1153 & 0.3244 & 0.7323 \\ 0.7535 & 0.0556 & 0.0085 \\ 0.0328 & 0.1550 & 0.0648\end{array}\right]$ consist of coordinate values of three convergent "means." $S_{1}=\left\{x_{2}\right\}$ is the strategy subspace of $F_{1} . S_{2}=\left\{x_{1}, x_{3}, x_{5}, x_{6}\right\}$ is the strategy subspace of $F_{2}$. $S_{3}=\left\{x_{4}\right\}$ is the strategy subspace of $F_{3}$ by correlation analysis.

The game equilibrium solutions are $X^{(3)}=\left(x_{1}^{*}, x_{2}^{*}, \ldots\right.$, $\left.x_{6}^{*}\right)=(13.721,224.926,21.142,3.718,24.574,3.313)$ after the third round iteration. Because it does not satisfy the convergence, the fourth game round is needed.

Impact factors of $X^{(3)}$ affecting the objective functions are shown in Table 4. Cluster 1 consists of design variables $x_{4}$ and cluster 2 consists of design variables $x_{2}$ and cluster 3 consists of design variables $x_{1}, x_{3}, x_{5}$, and $x_{6}$ by clustering calculation.

$\Gamma=\left[\begin{array}{lll}0.0978 & 0.5041 & 0.5603 \\ 0.7721 & 0.0160 & 0.1073 \\ 0.0325 & 0.1200 & 0.0831\end{array}\right]$ consist of coordinate values of three convergent "means." $S_{1}=\left\{x_{2}\right\}$ is the strategy subspace of $F_{1} . S_{2}=\left\{x_{1}, x_{3}, x_{5}, x_{6}\right\}$ is the strategy subspace of $F_{2}$. $S_{3}=\left\{x_{4}\right\}$ is the strategy subspace of $F_{3}$ by correlation analysis.

The game equilibrium solutions are $X^{(4)}=\left(x_{1}^{*}, x_{2}^{*}, \ldots\right.$, $\left.x_{6}^{*}\right)=(13.722,224.926,21.142,3.718,24.574,3.313)$ after the fourth round iteration. Because it does satisfy the convergence, the iteration loop stops.

Design variables values and objective functions values of the different game rounds are shown inTable 5.

5.3. Comparison of Results. Comparisons between the initial design, the traditional game design, and the design in this paper are shown to verify the validity of this method (the fuzzy clustering is adopted in the traditional game methodegoism design [12] and strategy subspaces cannot be adjusted along with the iteration loop).

(1) Comparison of Strategy Subspaces. Strategy subspaces are shown in Table 6 based on self-adaptive space division of design variables in this paper.

Strategy subspaces in the traditional game methodegoism design [12] are shown in Table 7.

The results of strategy subspaces are different in two methods and the strategy subspaces in this paper better promote the game iterative convergence through Tables 6 and 7. The final game equilibrium solutions can be obtained after 4 rounds in this paper but after 6 rounds in the traditional game method.

For self-adaptive method, because strategy subspaces of the $i$ th round are obtained based on the game equilibrium solution of the $(i-1)$ th round, there exists the strong relation between objectives and design variables, which can speed up the game convergence speed and improve the computational efficiency.

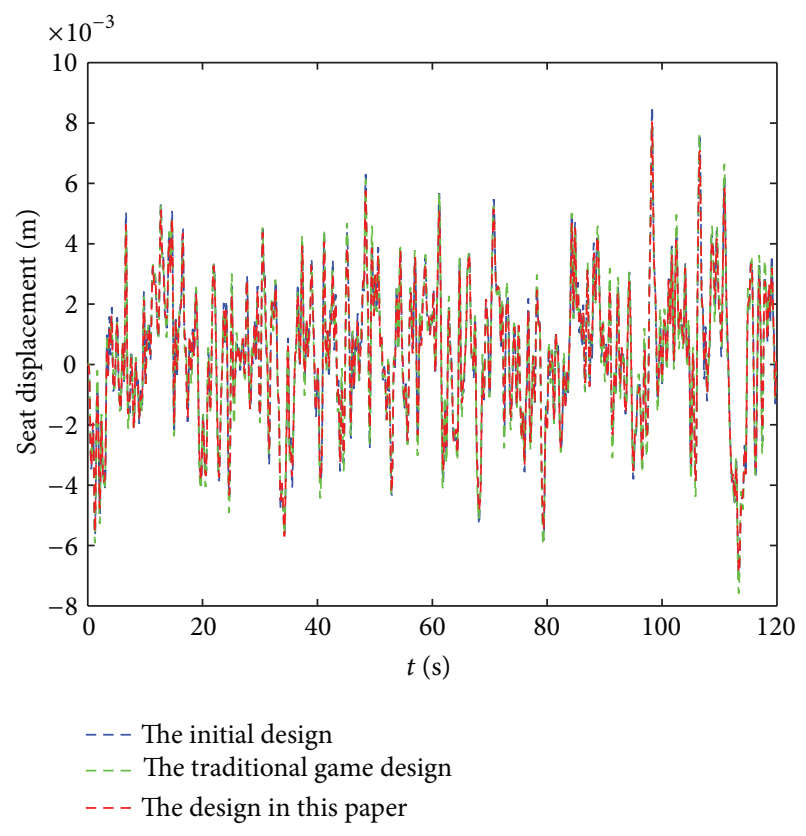

Figure 5: Comparison of seat displacement between the initial design, the traditional game design, and the design in this paper.

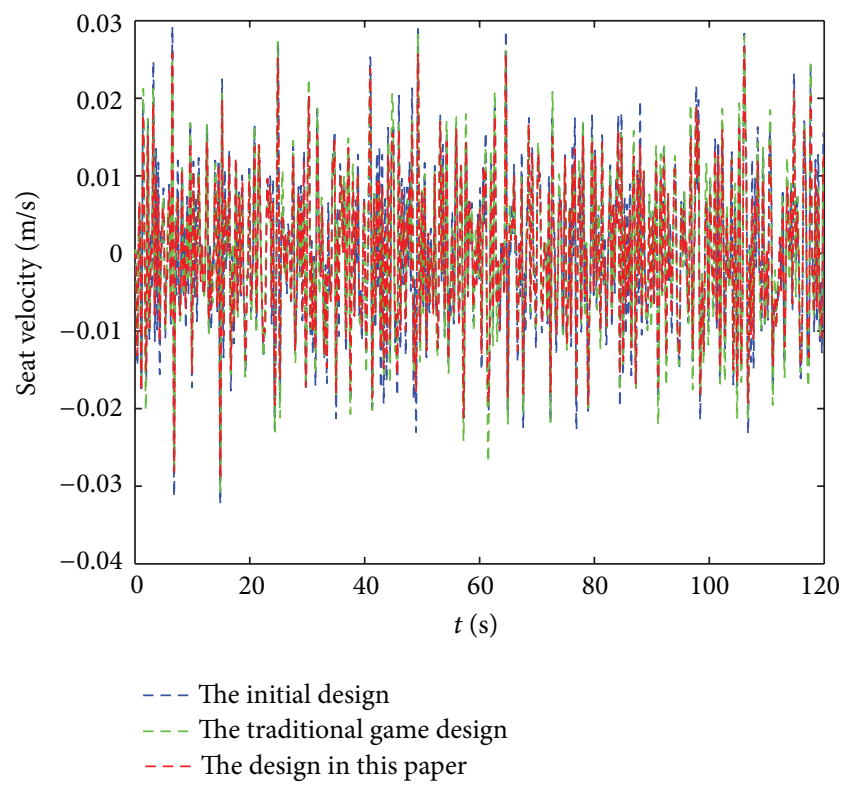

FIGURE 6: Comparison of seat velocity between the initial design, the traditional game design, and the design in this paper.

(2) Comparison of Objective Functions Values. From Table 8, we can see that the initial design values of the triobjective function $F_{1}, F_{2}$, and $F_{3}$ are $0.0815,0.0264$, and 5.245 , and the values in this paper are $0.0674,0.0245$, and $4.272 . F_{1}$ is improved by $17.30 \%$ and $F_{2}$ is improved by $7.19 \%$ and $F_{3}$ is improved by $18.55 \%$ compared with the initial design. Compared with the traditional game method-egoism design [12], the result in this paper has comprehensive advantage on triobjective functions and $F_{1}$ is improved by $3.57 \%$ and $F_{2}$ is improved by $0.40 \%$ and $F_{3}$ is improved by $2.95 \%$. 


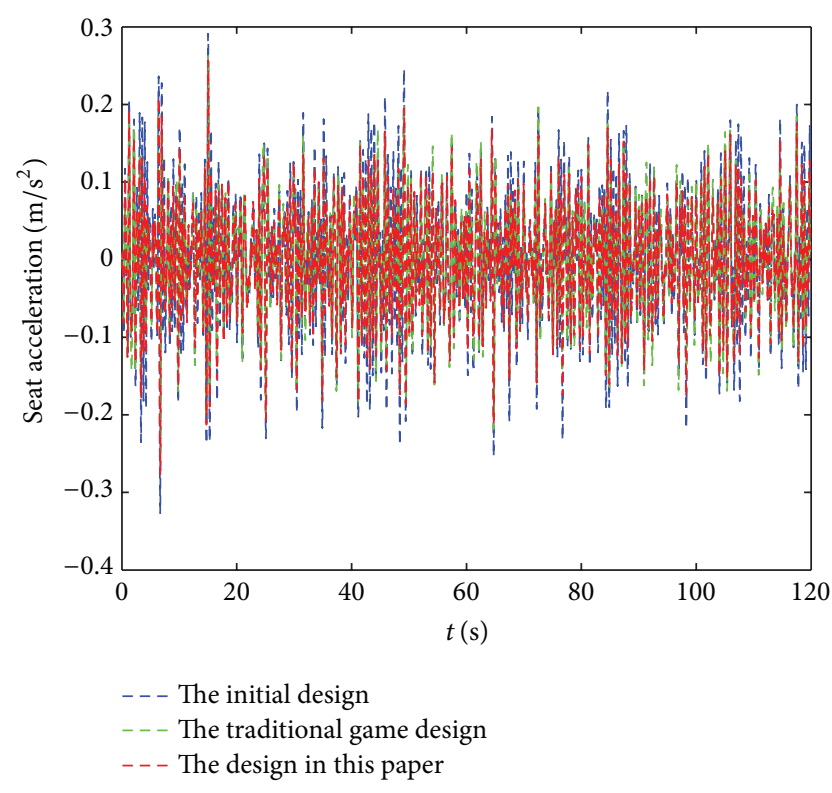

FIGURE 7: Comparison of seat acceleration between the initial design, the traditional game design, and the design in this paper.

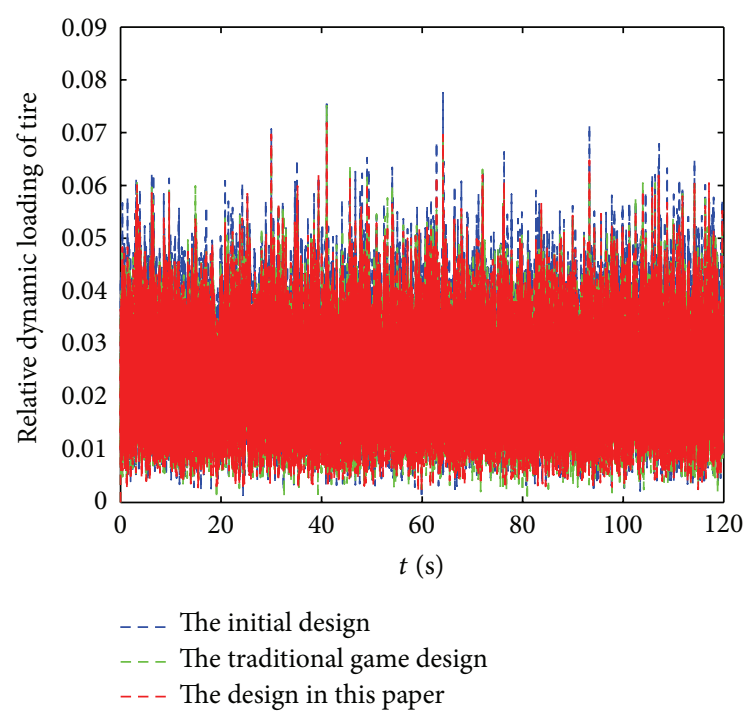

FIGURE 8: Comparison of relative dynamic loading of tire between the initial design, the traditional game design, and the design in this paper.

This illustrates that the method in this paper has better results than the traditional game method.

(3) Comparison of Performance Indicators. From Figures 5, 6, $7,8,9,10,11$, and 12 , performance indicators in this paper (seat displacement, velocity, acceleration, relative dynamic loading of the tire, and dynamic stroke) are significantly decreased compared with the initial design and are also better than the results of the traditional game method.

In the automobile design, power spectral density is used to describe the distributing situation of the power along

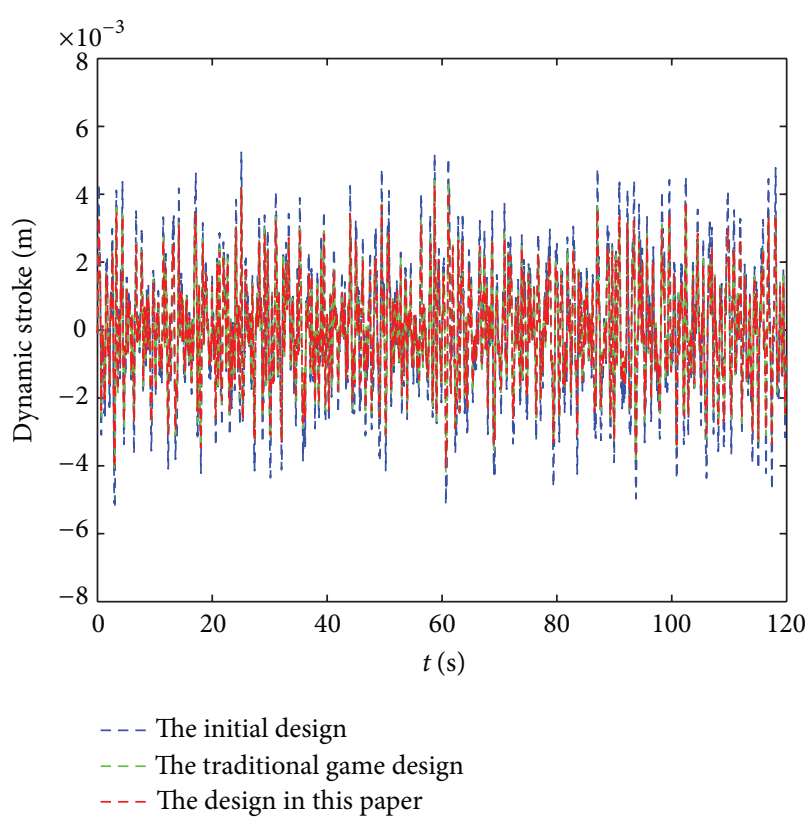

Figure 9: Comparison of right front wheel's dynamic stroke between the initial design, the traditional game design, and the design in this paper.

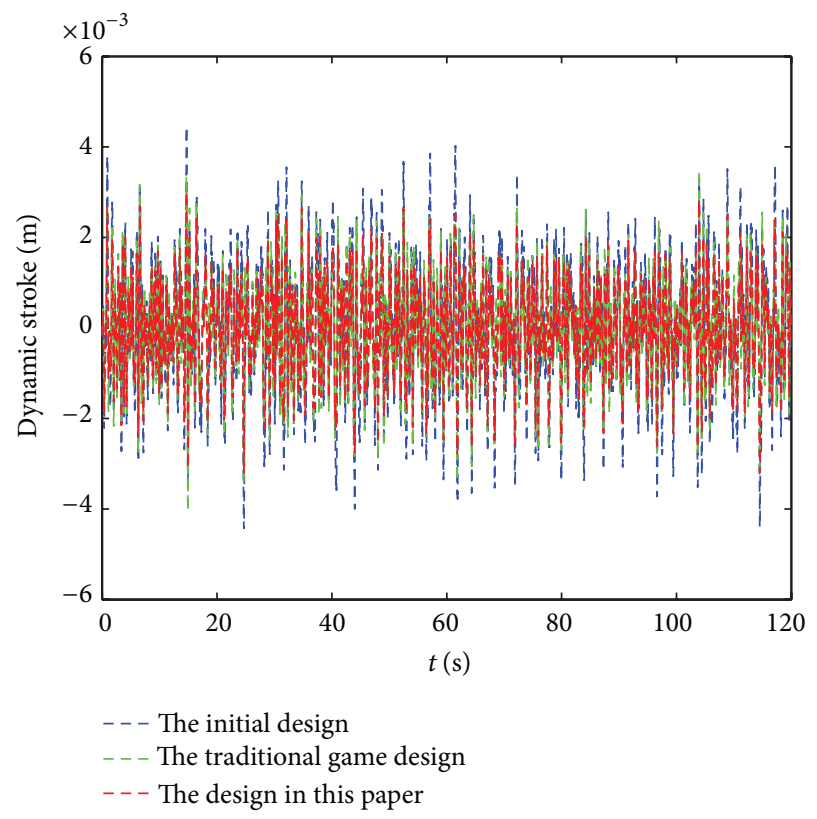

FIgURE 10: Comparison of left front wheel's dynamic stroke between the initial design, the traditional game design, and the design in this paper.

with the frequency for the accumulation index. Figure 13 demonstrates the distributing situation of the power spectral density along with the frequency for the seat acceleration. From Figure 13, we can see that the result obtained by the design in this paper is the best and its response is the least. As human body is very sensitive to vertical vibration and the most sensitive frequency range is $4 \sim 8 \mathrm{~Hz}$, we can see that the 


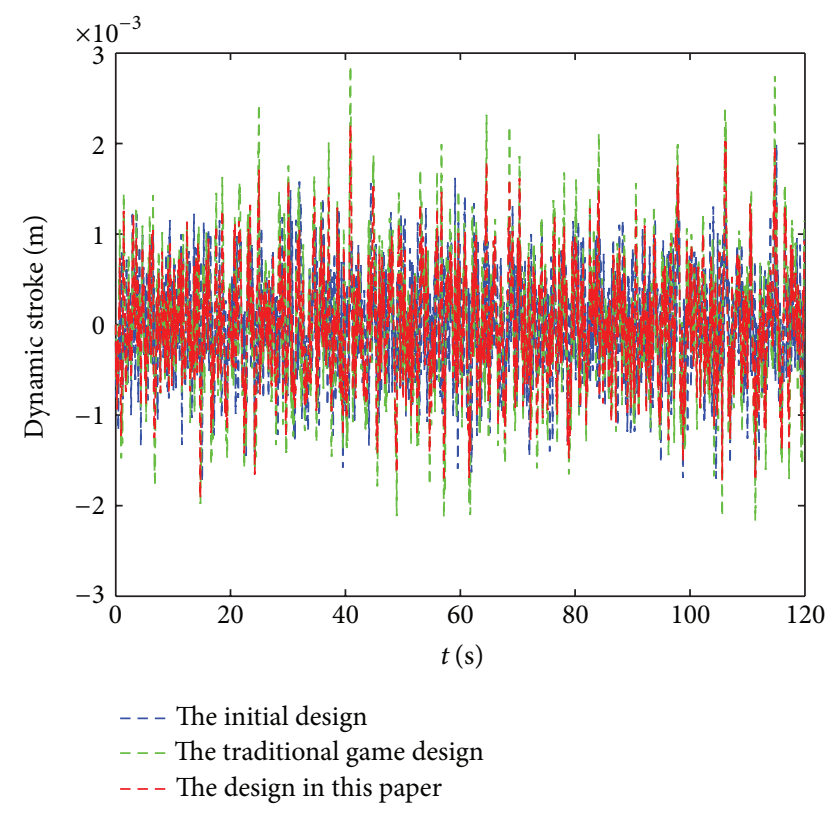

Figure 11: Comparison of left rear wheel's dynamic stroke between the initial design, the traditional game design, and the design in this paper.

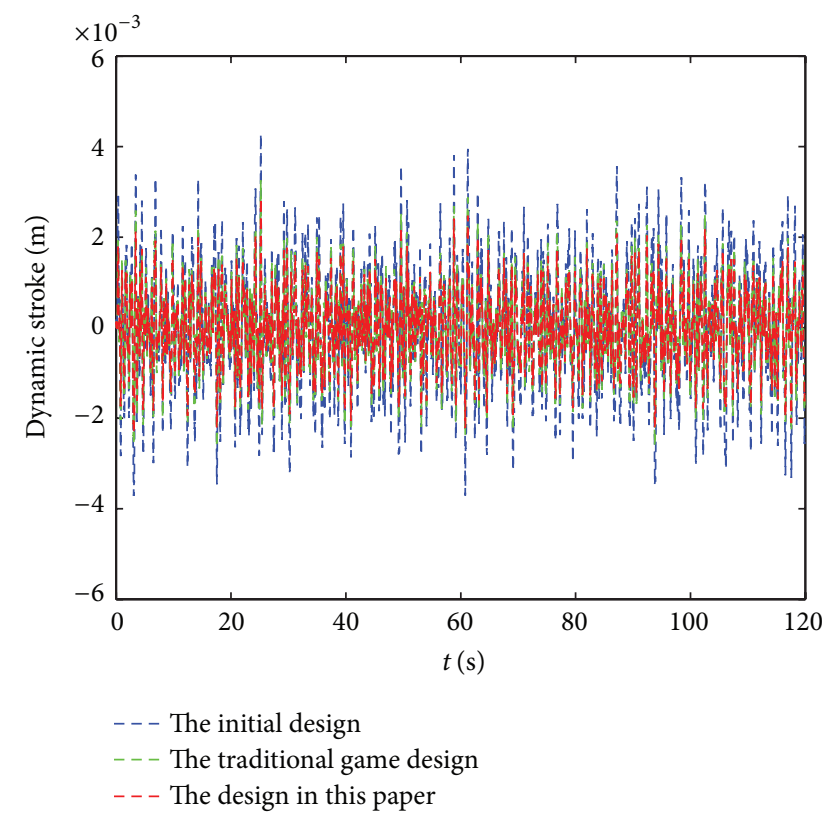

FIGURE 12: Comparison of right rear wheel's dynamic stroke between the initial design, the traditional game design, and the design in this paper.

peak value of the initial design is the maximum and is close to $4 \mathrm{~Hz}$ and the peak value of the design in this paper is the minimum and is far from $4 \mathrm{~Hz}$, so the ride comfort has been improved.

\section{Conclusions}

(1) The bionic mapping and the space mapping are established between the multiobjective optimization

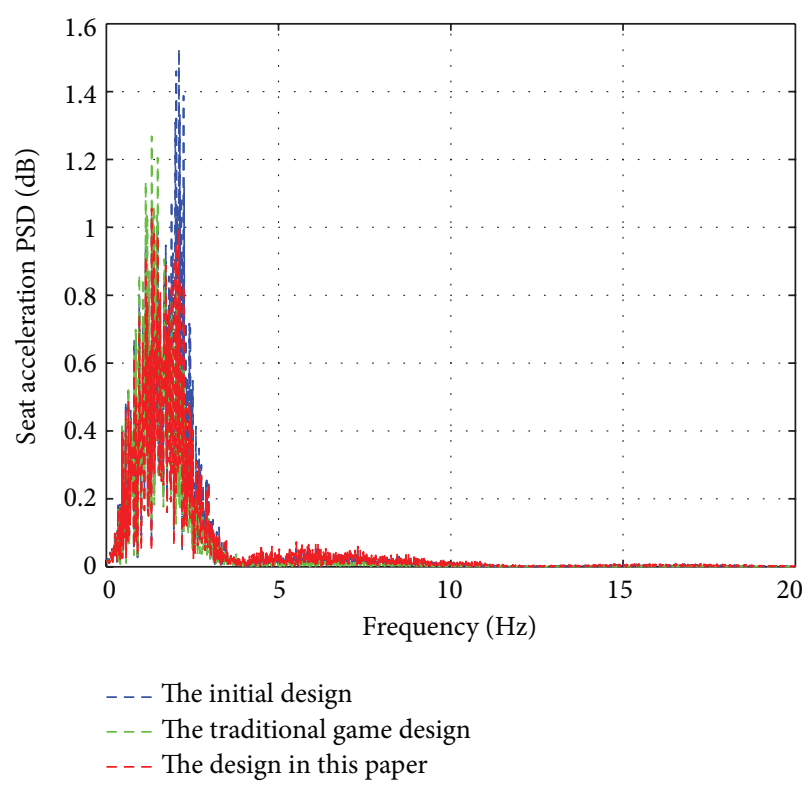

FIGURE 13: Comparison of the power spectral density for seat acceleration between the initial design, the traditional game design, and the design in this paper.

model and the game model. The key technology in the space mapping is that the design variables are divided into each player strategy subspaces. Aiming at disadvantages of fuzzy clustering, multiobjective game method based on self-adaptive space division of design variables is proposed by applying $K$-means clustering.

(2) Three-goal optimization is carried out for vehicle suspension system of eight degrees of freedom in this method and it is compared with the traditional game method. The results show that this method has better calculating automaticity, simplification, and universality for the complex engineering optimization problems and improves the computational efficiency and precision of multiobjective game method.

(3) Game method is especially suitable for the complex engineering structure design problems with lots of design variables and 2-4 objective functions. In the complex engineering structure problems, functions relationship between design variables and objective functions is complex and there exist the strong coupling and apparent conflict between the objective functions. Strategy change of one game player can cause chain reaction of other game players, which helps to carry out the negotiation and compromise between game players. But game method is not suitable for linear programming problems and the premise condition of game method is that the number of objective functions is less than the number of design variables. 


\section{Conflict of Interests}

The authors declare that there is no conflict of interests regarding the publication of this paper.

\section{Acknowledgments}

This project was supported by the National Natural Science Foundation of China (Grant no. 61375068) and Ministry of Education, Humanities and Social Sciences Research Projects (Grant no. 13YJAZH106).

\section{References}

[1] K. Deb, A. Pratap, S. Agarwal, and T. Meyarivan, "A fast and elitist multiobjective genetic algorithm: NSGA-II," IEEE Transactions on Evolutionary Computation, vol. 6, no. 2, pp. 182197, 2002.

[2] V. J. Amuso and J. Enslin, "The strength pareto evolutionary algorithm 2 (SPEA2) applied to simultaneous multimission waveform design," in Proceedings of the International Conference on Waveform Diversity and Design (WDD '07), pp. 407-417, June 2007.

[3] D. Lee, L. F. Gonzalez, J. Periaux, K. Srinivas, and E. Onate, "Hybrid-game strategies for multi-objective design optimization in engineering," Computers \& Fluids, vol. 47, pp. 189-204, 2011.

[4] J.-H. Lee, R. W. Diersing, and C.-H. Won, "Satellite attitude control using statistical game theory," in Proceedings of the American Control Conference (ACC '08), pp. 4856-4861, Seattle, Wash, USA, June 2008.

[5] S. M. R. Rafiei, M. H. Kordi, G. Griva, and A. Tenconi, "Nash genetic algorithm based optimal design of hysteresis inverters for active power filtering applications," in Proceedings of the IEEE Bucharest PowerTech Conference, pp. 1-6, Bucharest, Romania, July 2009.

[6] J. Periaux, H. Q. Chen, B. Mantel, M. Sefrioui, and H. T. Sui, "Combining game theory and genetic algorithms with application to DDM-nozzle optimization problems," Finite Elements in Analysis and Design, vol. 37, no. 5, pp. 417-429, 2001.

[7] J. F. Wang, Y. Z. Wu, and J. Périaux, "Decentralized multi-point optimization algorithms for multi-airfoil design in aerodynamics," Journal of Astronautics, vol. 24, pp. 71-77, 2003.

[8] T. Zhili and D. Jun, "Couplings in multi-criterion aerodynamic optimization problems using adjoint methods and game strategies," Chinese Journal of Aeronautics, vol. 22, no. 1, pp. 1-8, 2009.

[9] J.-A. Désidéri, "Cooperation and competition in multidisciplinary optimization: application to the aero-structural aircraft wing shape optimization," Computational Optimization and Applications, vol. 52, no. 1, pp. 29-68, 2012.

[10] Y. Hu and S. S. Rao, "Game-theory approach for multiobjective optimal design of stationary flat-plate solar collectors," Engineering Optimization, vol. 41, no. 11, pp. 1017-1035, 2009.

[11] N. Xie, Y. Cen, L. Sun, and L. Wang, "Multi-objective bionics design method based on mixed-behavior game," Chinese Journal of Theoretical and Applied Mechanics, vol. 40, no. 2, pp. 229237, 2008.

[12] W. Lu, X. N. Gang, S. C. Zhi, B. J. Han, and C. Y. Wan, "Multi-objective bionics design method of passive suspension parameters based on hybrid behavior game," Structural and Multidisciplinary Optimization, vol. 42, no. 3, pp. 371-386, 2010.
[13] C.-S. Lee, "Multi-objective game-theory models for conflict analysis in reservoir watershed management," Chemosphere, vol. 87, no. 6, pp. 608-613, 2012.

[14] X. Li, L. Gao, and W. Li, "Application of game theory based hybrid algorithm for multi-objective integrated process planning and scheduling," Expert Systems with Applications, vol. 39, no. 1, pp. 288-297, 2012.

[15] K. K. Annamdas and S. S. Rao, "Multi-objective optimization of engineering systems using game theory and particle swarm optimization," Engineering Optimization, vol. 41, no. 8, pp. 737752, 2009.

[16] N. Xie, L. Sun, J. Bao, and H. Fang, "Multi-objective game design of arch dam shape," Acta Mechanica Solida Sinica, vol. 27, pp. 200-206, 2007.

[17] Y. Maali, "A multiobjective approach for solving cooperative n-person games," International Journal of Electrical Power and Energy Systems, vol. 31, no. 10, pp. 608-610, 2009.

[18] J. R. J. Rao, K. Badhrinath, R. Pakala, and F. Mistree, "A study of optimal design under conflict using models of multi-player games," Engineering Optimization, vol. 28, no. 1-2, pp. 63-94, 1997.

[19] N.-G. Xie, R. Meng, Y. Ye, L. Wang, and Y.-W. Cen, "Multiobjective design method based on evolution game and its application for suspension," Structural and Multidisciplinary Optimization, vol. 47, no. 2, pp. 207-220, 2013.

[20] L. Chen and S. Li, "A computerized team approach for concurrent product and process design optimization," Computer Aided Design, vol. 34, no. 1, pp. 57-69, 2002.

[21] J. A. Hartigan, Clustering Algorithms, John Wiley \& Sons, New York, NY, USA, 1975.

[22] R. Guclu, "Fuzzy logic control of seat vibrations of a non-linear full vehicle model," Nonlinear Dynamics, vol. 40, no. 1, pp. 21-34, 2005. 


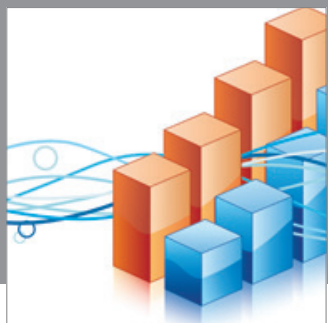

Advances in

Operations Research

mansans

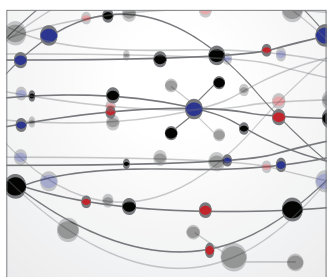

The Scientific World Journal
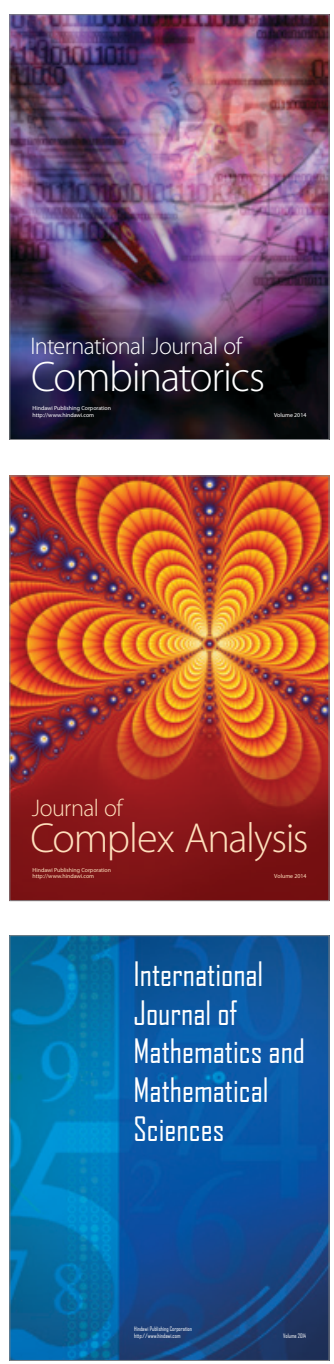
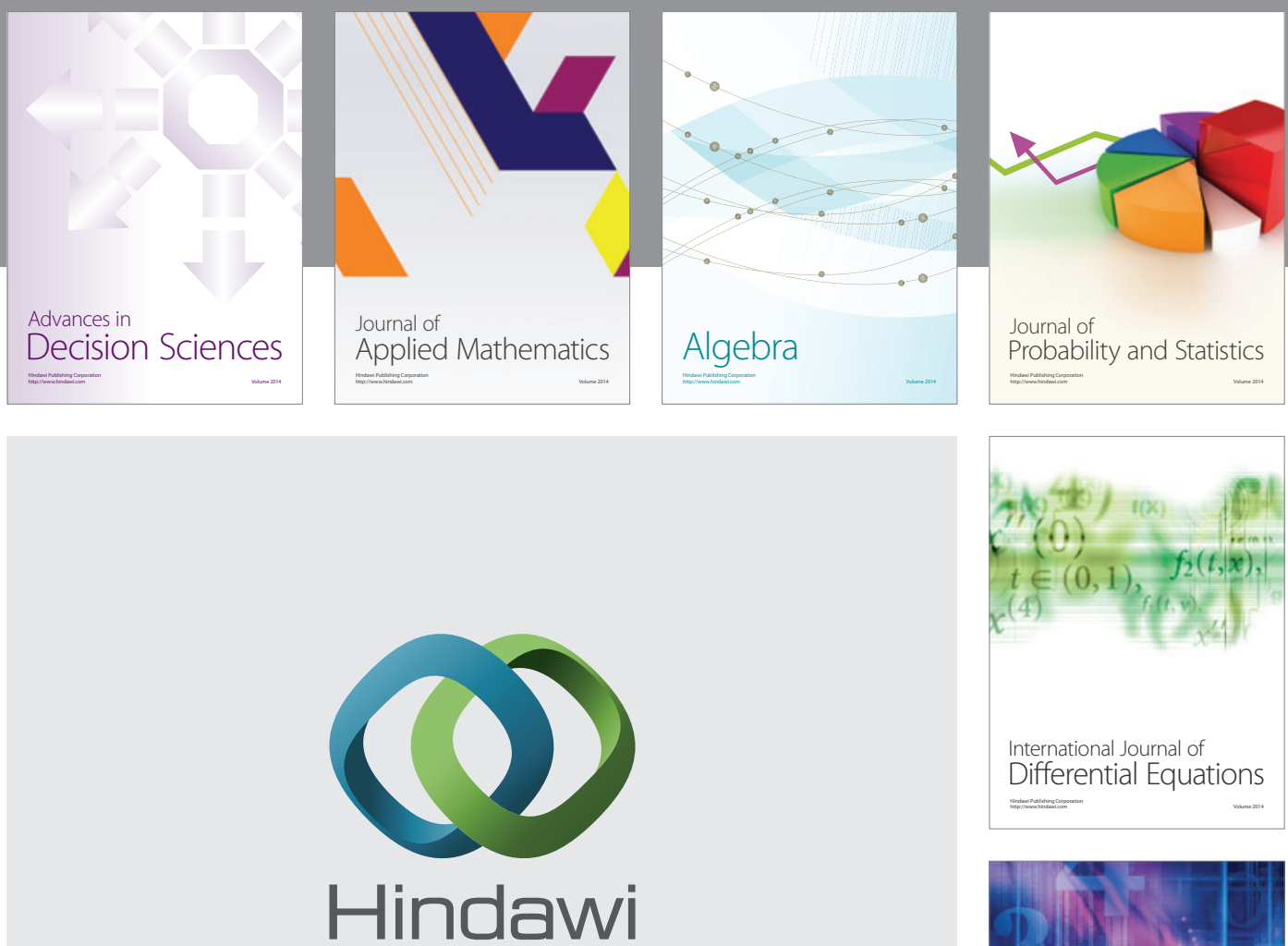

Submit your manuscripts at http://www.hindawi.com
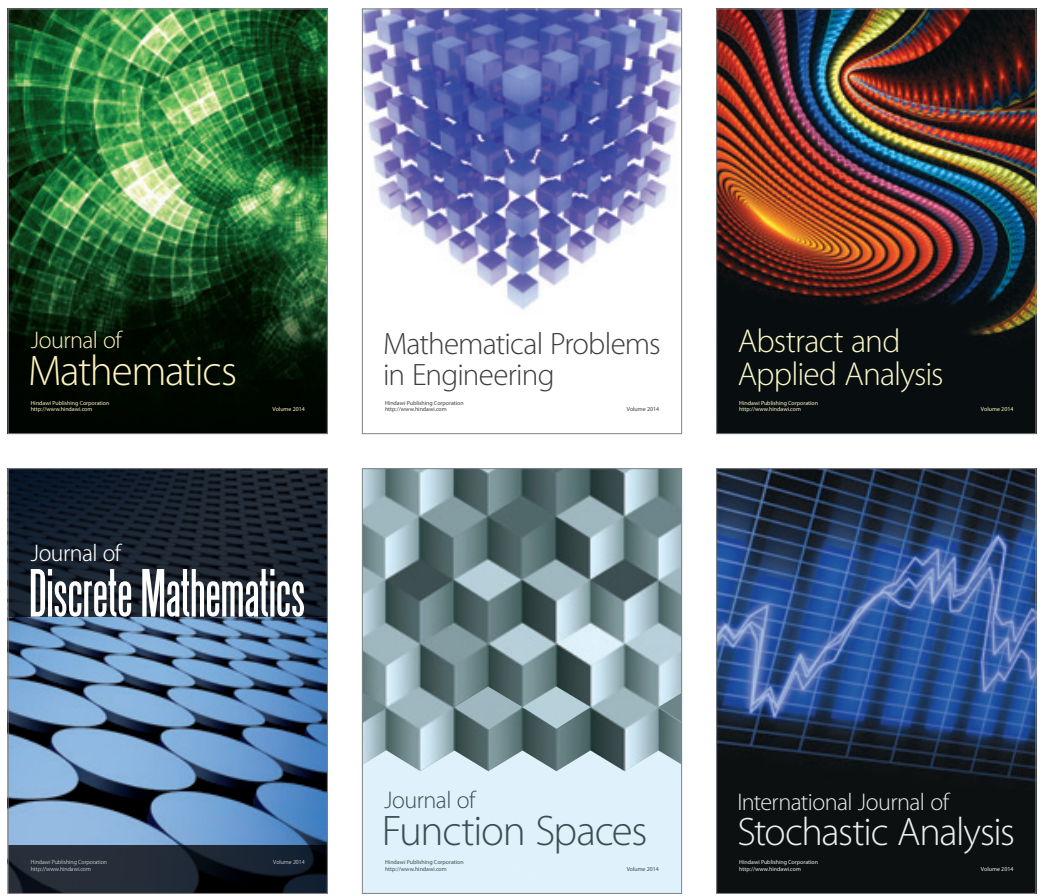

Journal of

Function Spaces

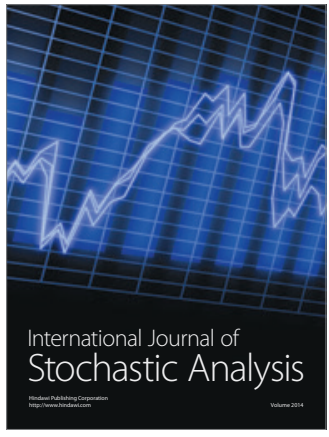

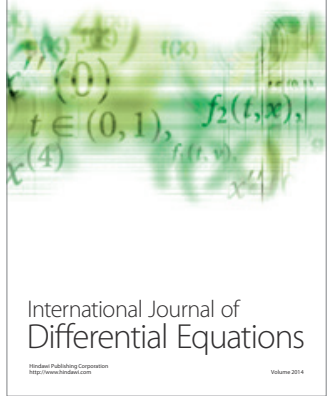
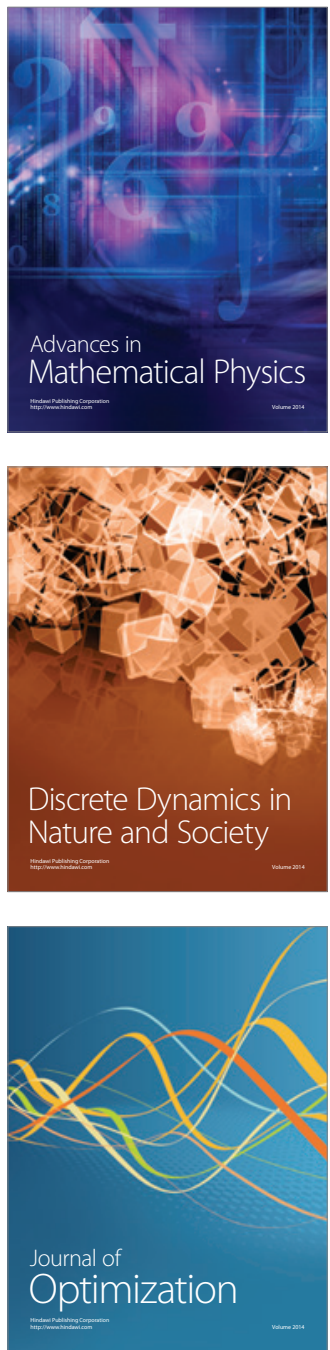